\title{
AGE-RELATED AND FUNCTION-DEPENDENT REGIONAL ALTERATIONS OF FREE L- AND D-ASPARTATE IN POSTEMBRYONIC CHICK BRAIN
}

\author{
Gergely Zachar, ${ }^{1}$ Tamás Jakó, ${ }^{2}$ István Vincze, ${ }^{2}$ Zsolt Wagner, ${ }^{2}$ Tamás TÁbi, ${ }^{2}$ \\ Eszter Bálint, ${ }^{1}$ SzIlvia Mezey, ${ }^{1}$ Éva SzöKÖ${ }^{2}$ and ANDrÁs Csillag ${ }^{1}$ \\ 1Department of Anatomy, Histology and Embryology, Semmelweis University, \\ Túzoltó u. 58, H-1094 Budapest, Hungary \\ ${ }^{2}$ Department of Pharmacodynamics, Semmelweis University, \\ Budapest, Hungary
}

(Received: October 6, 2017; accepted: December 8, 2017)

\begin{abstract}
D-aspartate (D-Asp) modulates adult neural plasticity and embryonic brain development by promoting cell proliferation, survival and differentiation. Here, developmental changes of the excitatory amino acids (EAAs) L-Glu, L-Asp and D-Asp were determined during the first postembryonic days, a time window for early learning, in selected brain regions of domestic chickens after chiral separation and capillary electrophoresis. Extracellular concentration (ECC) of EAAs was measured in microdialysis samples from freely moving chicks. ECC of D-Asp (but not L-EAAs) decreased during the first week of age, with no considerable regional or learning-related variation. ECC of L-Asp and L-Glu (but not of D-Asp) were elevated in the $\mathrm{mSt} / \mathrm{Ac}$ in response to a rewarding stimulus, suggesting importance of Asp-Glu co-release in synaptic plasticity of basal ganglia. Potassium-evoked release of D-Asp, with a protracted transient, was also demonstrated. D-Asp constitutes greater percentage of total aspartate in the extracellular space than in whole tissue extracts, thus the bulk of D-Asp detected in tissue appears in the extracellular space. Conversely, only a fraction of tissue L-EAAs can be detected in extracellular space. The lack of changes in tissue D-Asp following avoidance learning indicates a tonic, rather than phasic, mechanism in the neuromodulatory action of this amino acid.
\end{abstract}

Keywords: D-aspartic acid - avian brain - postembryonic development - arcopallium - amygdala

\section{INTRODUCTION}

L-Aspartic acid (L-Asp) has neurotransmitter properties in the brain of various vertebrates $[17,28]$. L-Asp together with L-glutamate (L-Glu) are co-released in the striatum of young domestic chicks [45]. Of particular interest is the potential role of excitatory amino acids (EAAs) during the first postembryonic days, a sensitive time window for early adaptive brain plasticity such as imprinting of precocial birds. Another extensively studied early learning model is passive avoidance learning (PAL), in which hatchlings of domestic chicks learn to avoid bad tasting food-like objects [36]. Early learning leads to an increased number of new neurons in the medial striatum (mSt) [10] - an area partially corresponding to the nucleus accum-

*Corresponding author; e-mail address: gzachar@gmail.com 
bens, as confirmed also by our laboratory [3] - and the intermediate medial mesopallium (iMM), an associative cortex homologue. Both regions participate in PAL of chicks together with a third key area called the arcopallium (Arco), which is largely homologous to the mammalian amygdala [35]. Both in the $\mathrm{mSt}$ and iMM glutamate dependent LTP has been already detected [24].

Unlike D-glutamate, the enantiomer of L-Asp, D-aspartic acid (D-Asp) occurs in the brain of mollusks [8], mammals [11,21] and birds [30]. As recently discovered, D-Asp is synthesized by the serine-racemase enzyme [23]. Although its function remains disputed, D-Asp has been implicated in the early development of the brain due to its relatively high concentration during embryonic development [20, 21]. Dynamic changes of D-Asp in the CNS during embryonic development have been described by several studies, however, less data is available on postembryonic alterations [20, 43]. It is suggested that D-Asp also modulates adult neural and behavioural plasticity as a signaling factor $[12,39]$. Glutamate transmission dependent synaptic potentiation [24] and synaptic remodeling [38] are required in the $\mathrm{mSt}$ and iMM for memory formation during PAL. In order to assess the relevance of EAAs to brain development and (early adaptive) learning, it is essential to measure their resting levels in the brain regions crucial for PAL. Given the known variability and age dependence of D-Asp in embryonic mammalian brain [20,30], it seemed logical to extend tissue analysis of D-Asp (parallel with the L-enantiomers) to postembryonic development of the chicken until adulthood. By doing so, any developmental alterations, which could otherwise confound the analysis of functional (e.g. learning-evoked) changes, can duly be taken into account. To separate that contingent of amino acids which contributes to the metabolic pool of cells from that which participates in signaling, we investigated the percentage of tissue EAAs appearing in the extracellular space, as well as the ratios between the different L- and D-enantiomers.

In the present study, L-Glu and L-Asp were measured in tissue samples from brain regions relevant to PAL (iMM, mSt, Arco), and from the cerebellum $(\mathrm{Cb})$ as control region. The above regions were also tested for age-related changes of L-Asp as well as L-Glu, in chickens of 2 to 62 days of age. We also measured amino acid concentrations in the above-mentioned regions after passive avoidance training to detect any changes related to behavioural/synaptic plasticity. For a refined analysis of the questions posed, capillary electrophoresis coupled with laser induced fluorescence detection was used to quantify the excitatory amino acids (EAAs) extracted from tissue homogenates [41]. Separation of D- and L-enantiomers was supported by a recently reported method of chiral separation [42]. A further extension of the method, an attempt was made here to detect D-Asp also in microdialysis samples, collected from freely moving chicks, enabling the monitoring of function-dependent dynamic changes. 


\title{
MATERIALS AND METHODS
}

\begin{abstract}
Animals
Young unsexed Hunnia-broiler chicks (153 in total), purchased from a local company (Bábolna Kft., Budapest, Hungary) were used. Chicks were kept in groups of 10 in $33 \times 40 \times 25 \mathrm{~cm}$ plastic boxes, unless stated otherwise, until the 8 th day of age, and then transferred to larger cages in groups of 4 individuals until they have reached maturity (62 days of age). For all animals water and food were available ad libitum and light/ dark cycles were 12/12 h. All animals were kept and treated according to the regulations of the ethical committee of the Semmelweis University, and all experiments were approved by the Ethical Committee on Animal Experimentation, and permitted by the Food Chain Safety and Animal Health Directorate of the Government Office for Pest County (Permit Number: XIV-I-001/2269-4/2012). Procedures were in harmony with the EU Council directives on laboratory animals (86/609/EEC).
\end{abstract}

\section{Behavioural procedure of passive avoidance training and recall}

The training procedure was carried out as described by Gibbs et al. [16]. Briefly, dayold chicks were placed in small open boxes $(20 \times 25 \times 25 \mathrm{~cm})$ upon arrival. Chicks $(\mathrm{n}=84)$ were kept in pairs during the experiment to reduce isolation stress. After an at least 3-hour accommodation period a dry black bead was introduced as a pretraining stimulus. Colored glass beads fixed to the end of thin metal stick were used as stimuli. Five minutes later a red bead was presented, covered either with water or methyl anthranylate (MeA), a harmless but bitter substance. The chicks in the MeA trained group displayed disgust response (head shake, retreat, gaping) when they tasted MeA. Five minutes, 6 hours or 24 hours later, dry blue and red beads were presented to the chicks for 30 seconds each, to test the retention of memory. All chicks were two days old at the time of memory tests, therefore, the accommodation period at the beginning of the training varied between 3 and 24 hours according to the delay of the recall. In the 24-h group, chicks were trained on the preceding day. Those chicks that did not peck on any stimulus during pretraining or training (due to lack of alertness, drowsiness) were excluded from the experiment $(n=12)$. Those chicks in the water trained group that refrained from pecking during recall, as well as those chicks in the MeA-trained group that pecked on the red bead were also excluded from further analysis $(n=16)$. The elimination procedure meant to ensure that two homogeneous experimental groups (one that was exposed to MeA and did duly show avoidance, and another that was not even exposed to the aversive substance and did not show avoidance either). 


\section{Tissue sampling for chemical analysis}

Chicks ( $\mathrm{n}=61)$ were euthanized (by deep ketamine-xylazine anaesthesia) and decapitated at different ages $(2,4,8$ and 62 days). Their brains were dissected and coronal slabs containing the respective brain regions were prepared by standardized dissection using a plastic brain mold. Rectangular samples of 1-3 mm width were dissected under a stereomicroscope with a pointed scalpel blade (Fig. 1). For samples from the $\mathrm{mSt}$, iMM the slab extending between the rostrocaudal coordinates 6.16 and $4.72 \mathrm{~mm}$ were used, whereas for samples of the arcopallium, the rostral and caudal limits of the slab were 4.72 and $3.28 \mathrm{~mm}$, respectively (for the coordinates see Puelles [32]), (Fig. 1A, B). The cerebellar samples were taken from the dorsal cerebellum, dissected directly from the whole brain (not shown). Tissue samples were weighed and frozen immediately in pre-weighed vials on dry ice and stored at $-80{ }^{\circ} \mathrm{C}$ until further processing. Further processing was carried out as described below.

A

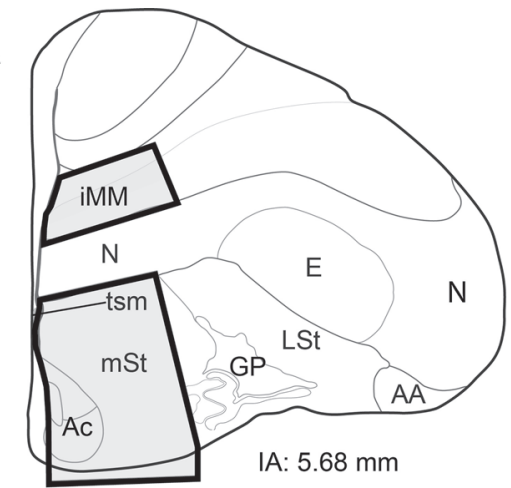

C

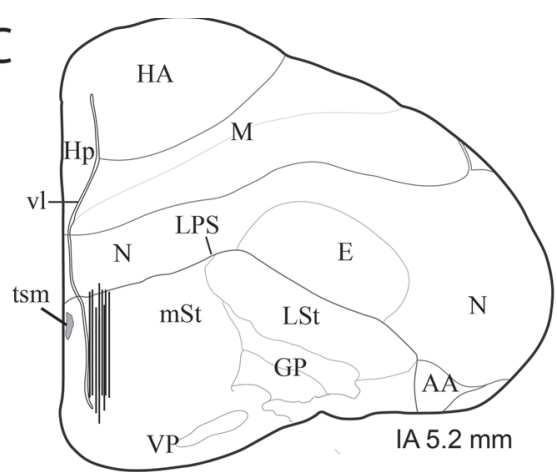

$\mathrm{B}$

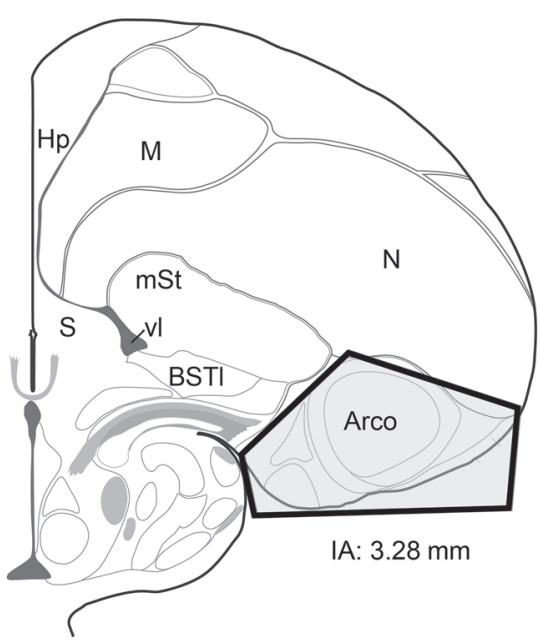

Fig. 1. Approximate borders (bold frames) of regions dissected from the brains of domestic chicks (A, B) and the location of the active part of the microdialysis probes (C) as represented according to the stereotaxic atlas of Puelles [32]. IA: rostrocaudal coordinates as distances from the interaural plane. Abbreviations: AA: anterior arcopallium, Ac: $\mathrm{n}$. accumbens, Arco: arcopallium, BSTl: lateral bed nucleus of the stria terminalis, E: entopallium, GP: globus pallidus, HA: hyperpallium apicale, Hp: hippocampus, iMM: intermediate medial mesopallium, LPS: lamina palliosubpallialis, LSt: lateral striatum, M: mesopallium, mSt: medial striatum, N: nidopallium, S: septum, tsm: tractus septomesencephalicus, vl: lateral ventricle, VP: ventral pallidum 


\section{Surgery and histology}

Chicks were operated on the day of arrival. The animals were anaesthetised by intramuscular injection of mixed ketamine and xylazine ( 40 and $8 \mathrm{mg} / \mathrm{bwkg}$, respectively). The chicks were fixed onto a stereotaxic frame. A microdialysis probe (EI-A-Z-1; $1.5 \mathrm{~mm}$ active surface length, Eicom, Kyoto, Japan) was implanted into the left medial striatum and fixed onto the skull with dental cement (Duracryl, Spofa Dental, Praha, Czech Republic). Implantation coordinates were $4.0 \mathrm{~mm}$ anterior from breg$\mathrm{ma}, 0.85 \mathrm{~mm}$ lateral from midline and $5.8 \mathrm{~mm}$ ventral from brain surface. The coordinates were in agreement with previous lesion and pathway tracing studies on the ventrobasal forebrain of the domestic chicken $[3,26,46]$. After the implantation, the animals were allowed to recover from the operation for at least $12 \mathrm{~h}$ without food and water (this is standard procedure for day-old domestic chicks supported by their yolk sac). Microdialysis samples were collected 1 day after surgery. After the experiments the chicks were sacrificed by decapitation under deep ketamine-xylazine anaesthesia. For verification of probe location, the brains were dissected and immersed into fixative (4\% paraformaldehyde in $0.1 \mathrm{M}$ phosphate buffer) for at least $24 \mathrm{~h}$. Sixtymicrometer-thick coronal sections were cut from the brain of each animal covering the area adjacent to the insertion point of the probe. The sections were counterstained with cresyl violet (Nissl stain), the location of the probe was determined by microphotography, and documented on a composite diagram (Fig. 1C).

\section{In vivo microdialysis procedure}

Immediately after surgery the chicks $(\mathrm{n}=8)$ were placed into an open-field box with a one-way mirror wall, where they were allowed to recover. The microdialysis probe was perfused with artificial cerebrospinal fluid (ACSF) $\left[120 \mathrm{mM} \mathrm{Na}^{+}, 6 \mathrm{mM} \mathrm{K}^{+}\right.$, $2 \mathrm{mM} \mathrm{Ca}^{2+}, 125 \mathrm{mM} \mathrm{Mg}^{+}, 129 \mathrm{mM} \mathrm{CI}^{-}, 125 \mathrm{mM} \mathrm{H}_{2} \mathrm{PO}_{4}^{-}, 21 \mathrm{mM} \mathrm{HCO}_{3}^{-}$(pH 7.4)], at a flow rate of $0.3 \mu \mathrm{l} / \mathrm{min}$, using a microinjection pump (Stoelting, Dublin, Ireland). The probe was attached to the pump through polyethylene tubing via a liquid switch and swivel (CMA Microdialysis AB, Solna, Sweden) to enable rapid changing of the perfusion media and to avoid convolution of the tubing. The post-stimulus delay of response was adjusted according to the flow rate and the length of the tubing. After a stabilization period of $18-20 \mathrm{~h}$, samples were collected in $200 \mu \mathrm{l}$ polypropylene tubes at 20 min intervals, placed on dry ice and later stored at $-80^{\circ} \mathrm{C}$ until further analysis.

In the experiment, after collecting 3 samples $(60 \mathrm{~min})$ the birds were allowed to drink tap water ad libitum for $20 \mathrm{~min}$ (1 sample). One hundred minutes later, $50 \mathrm{mM}$ $\mathrm{KCl}$ containing ACSF was perfused through the probe for $20 \mathrm{~min}$. The $\mathrm{Na}^{+}$content of ACSF was reduced correspondingly to maintain osmolality. After each stimulus the perfusion medium was switched back to standard ACSF and further samples were collected. 


\section{Analysis of samples}

For brain tissue extracts, samples were mixed with $10 \mu \mathrm{l} / \mathrm{mg}$ (wet tissue) ice-cold acetonitrile/water (2:1) mixture and homogenized by sonication for $5 \mathrm{~s}$, followed by centrifugation at $3,000 \times g$ for $10 \mathrm{~min}$ at $4{ }^{\circ} \mathrm{C}$. The supernatant was collected and further diluted ten times with artificial cerebrospinal fluid (ACSF) prior to derivatization. Once in a liquid phase, the samples (including microdialysis samples) were further processed for analysis as follows.

Capillary electrophoresis measurements were performed with a P/ACE MDQ capillary electrophoresis system controlled by the 32 Karat software version 5.0 (Beckman Coulter, Brea, CA, USA). The instrument was coupled with a laserinduced fluorescence detector, equipped with an argon-ion laser. Excitation and emission wavelengths were 488 and $520 \mathrm{~nm}$, respectively. Separations were carried out in fused-silica capillaries of $75 \mu \mathrm{m}$ internal diameter and $365 \mu \mathrm{m}$ outer diameter (Polymicro Technology, Phoenix, AZ, USA), coated with in situ polymerized linear polyacrylamide. The total and the effective capillary lengths were 60 and $50 \mathrm{~cm}$, respectively. We applied a recently developed method of chiral separation [42] for the simultaneous measurement of excitatory amino acid (EAA) enantiomers. D-amino acids are rarely incorporated into proteins [15, 27], therefore most tissue content is expected to represent the unbound (free) form. Our method exclusively measures this form of amino acids. To achieve appropriate detection sensitivity, fluorescent derivatization with 4-fluoro-7-nitro-2,1,3-benzoxadiazole was applied together with $1 \mu \mathrm{M}$ g-carboxy-glutamate as an internal standard. Samples were introduced into the capillary by pressure $(20 \mathrm{~s}, 6895 \mathrm{~Pa})$. The background electrolyte was $100 \mathrm{mM}$ borate buffer $\mathrm{pH} 8.5$ containing $8 \mathrm{mM}$ heptakis (2,6-di-O-methyl)- $\beta$ cyclodextrin and $5 \mathrm{mM}$ 6-monodeoxy-6-mono(3-hydroxy)propylamino- $\beta$-cyclodextrin as chiral selectors. Typically, $400 \mathrm{~V} / \mathrm{cm}$ electric field was applied. For detailed description of the derivatization and electrophoresis methods see [42]. Detection limit (LOD) and quantification limit (LOQ) for D-Asp were 17 and 50 $\mathrm{nmol} / \mathrm{L}$, respectively.

\section{Statistical analysis}

The EAA concentrations were compared by ANOVA using a full factorial general linear model (GLM, factors: age, training type, recall time in different experiments). Different brain regions of the same individual were used as within subject factors (RM ANOVA). Data were logarithmically (ln) transformed when required for matching the data assumptions of ANOVA. Degrees of freedom (d.f.) statistics were corrected in RM ANOVAs using the Greenhouse-Geisser method when sphericity was not assumed, however, uncorrected d.f. are reported under Results. Experimental groups by age or species were compared pairwise using Tukey's post-hoc tests. Comparisons between brain regions within the same animals were carried out using paired $t$-tests with Sidak-Holm adjustment of $\mathrm{p}$ values. In the case of microdialysis 
samples, relative changes standardized by baseline concentrations were compared by non-parametric test (Wilcoxon Signed Rank test). It has to be noted that the results on D-Asp concentration in microdialysis samples were based on those 5 animals, in which the detection limit was attained. Level of significance was $p<0.05$.

\section{RESULTS}

\section{Age- and brain region-related changes in the tissue content of amino acids}

D-Glu was not detected in any of the samples, whereas D- and L-Asp as well as L-Glu could be measured in all samples. In the domestic chicken, neither the brain region $\left(\mathrm{F}_{3,177}=2.29, \mathrm{p}=0.09\right)$ nor the interaction between region and age $\left(\mathrm{F}_{9,177}=0.82, \mathrm{p}=0.58\right)$ had significant effect on the concentration of L-Asp (Fig. 2B). Both L-Asp (age, ANOVA: $\mathrm{F}_{3,59}=6.61, \mathrm{p}=0.018$, Fig. $2 \mathrm{~B}$ ) and L-Glu (age, ANOVA: $F_{3,57}=4.79, p=0.005$, Fig. $2 \mathrm{C}$ ) showed some dependence on age, mainly due to a transient decrease around day 4. Region also had a significant effect on L-Glu concentration: it was least abundant in the $\mathrm{mSt} / \mathrm{Ac}$ (RM ANOVA: $\mathrm{F}_{3,171}=12.52$, $\mathrm{df}=3, \mathrm{p}=0.005$ ).

Age had a significant effect on D-Asp concentration in four observed regions in the chicken brain (ANOVA: $\mathrm{F}_{3,57}=23.28, \mathrm{p}<0.001$ ) with a marked drop between days 2 and 4 (Tukey's post-hoc test: $\mathrm{p}<0.001$ ) and remaining low afterwards (Fig. 2A). Brain region had no effect on D-Asp concentration $\left(\mathrm{F}_{3,171}=1.64, \mathrm{p}=0.18\right)$ and there was no interaction between region and age either $\left(\mathrm{F}_{9,171}=0.82, \mathrm{p}=0.60\right)$. When the concentration of D-Asp was expressed as percentage ratio (D-Asp over L-Asp plus D-Asp), the difference between a clear and monotonous, age-dependent decrease of $\mathrm{D}$-Asp became even more evident (effect of age on D-Asp ratio: $\mathrm{F}_{3,57}=33.6$, p $<0.001$, Fig. 2D).

\section{Effect of passive avoidance training and recall on the tissue content of amino acids (data not shown)}

Neither the training type (water, MeA, $\mathrm{F}_{1,44}=1.54, \mathrm{p}=0.22$ ), nor recall time ( $5 \mathrm{~min}$, 6 hours or 24 hours, $\left.F_{2,44}=0.75, \mathrm{p}=0.48\right)$, nor their interaction $\left(\mathrm{F}_{2,44}=0.70\right.$, $\mathrm{p}=0.48$ ) had a significant effect on the concentration of D-Asp. There was no overall difference in D-Asp concentration between the four brain regions either $\left(\mathrm{F}_{3,132}=1.00\right.$, $p=0.40$ ) and none of the interactions between the main effects were significant. Similar results were obtained in the case of L-Asp concentrations: neither the main effects, nor the interactions were significant. Similarly to the previously described age-related changes, again, the concentration of L-Glu was not found to be uniform in all brain regions $\left(\mathrm{F}_{3,129}=5.61, \mathrm{p}=0.001\right)$. As revealed by tests of within-subject contrasts, $\mathrm{mSt}$ contained less L-Glu than any of the other three regions $\left(\mathrm{F}_{1,43}>5.76\right.$, 

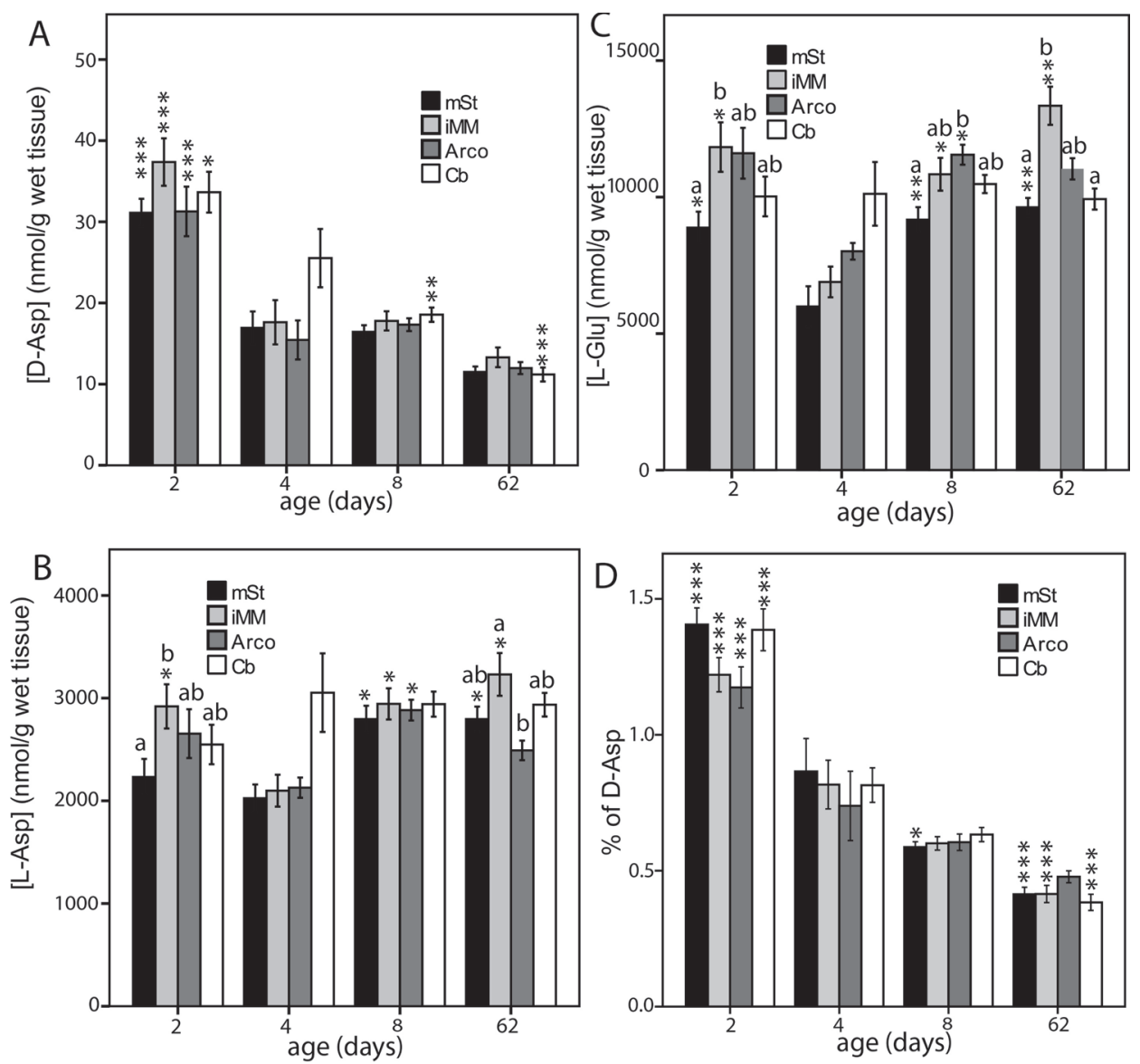

Fig. 2. Effect of age on D-Asp (A, D), L-Asp (B) and L-Glu (C) concentrations (mean \pm S.E.M.) in four brain regions of the domestic chick. (D) - D-Asp over total Asp ratio. Asterisks represent significant difference with day 4 values as base value (Tukey post-hoc tests $* p<0.05, * * * p<0.001$ ). The different letters of alphabet above columns represent significant difference between the brain regions within the same age group (paired $t$-tests: $\mathrm{p}<0.05$ )

$\mathrm{p}<0.022$ ). None of the other main effects (training type, recall time) or any of the interactions were significant.

\section{Effect of reward and high potassium stimuli on the extracellular levels of amino acids}

Against the background of known free EAA concentrations in tissue extracts, we then tested the dynamic changes of extracellular L- and D-Asp and L-Glu in the Ac/mSt region, using in vivo microdialysis of freely moving chicks. Both L-amino acids 


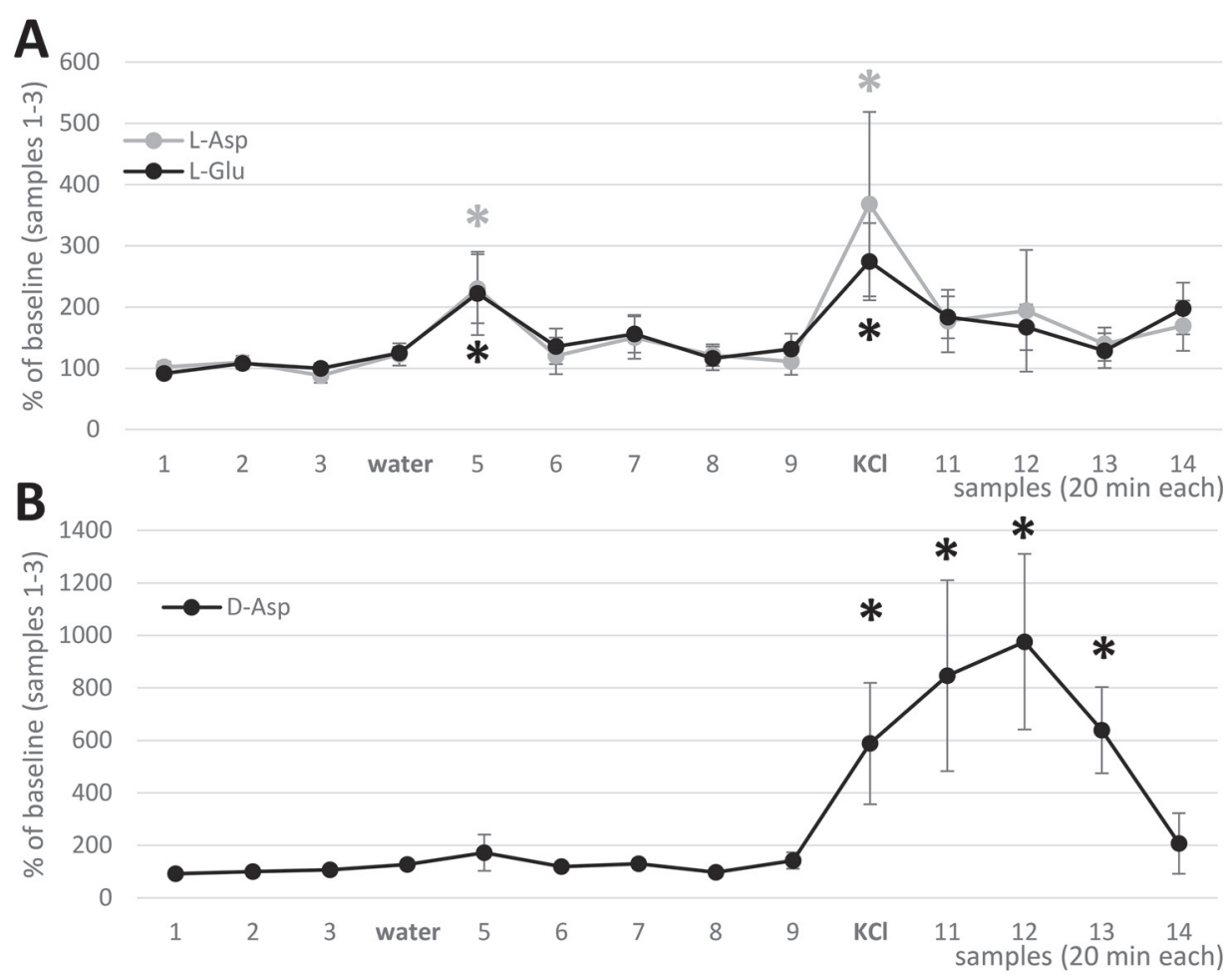

Fig. 3. In vivo microdialysis recordings from 2-day-old freely moving domestic chicks, with probe location in the $\mathrm{mSt} / \mathrm{Ac}$ region. A: Effect of rewarding stimulus and high potassium on the extracellular level of L-Asp and L-Glu. B: Effect of rewarding stimulus and high potassium on the extracellular level of D-Asp. Mean \pm S.E.M., asterisks represent significant difference with baseline values (Wilcoxon Signed Rank test, $\mathrm{p}<0.05$ )

showed simultaneous transient elevation on water administration (a reward stimulus for thirsty chicks) (Fig. 3A). Similar but greater elevation of L-EAA levels was evoked by the non-specific stimulus, high potassium. Both L-Glu and L-Asp showed similar characteristics of transients, the overall Asp/Glu ratio being $20-30 \%$ (Table 1). D-Asp showed only a slight, non-significant elevation after water administration, but a robust (ca. tenfold) increase did follow potassium stimulation (Fig. 3B). Notably, the peak of D-Asp transient does not coincide with the period of high $\mathrm{K}$ administration, it merely follows the event with a delay of at least $20 \mathrm{~min}$.

\section{Comparison of extracellular and whole tissue concentrations of amino acids}

The amino acid concentrations and ratios in microdialysis samples in various experimental conditions are tabulated in Table 1, also compared with the relevant values 
from tissue extracts. The L-Asp ratio proved to be remarkably stable throughout the microdialysis samples and also similar to the ratio observed in tissue extracts. Notably, however, the ratio of D-Asp was almost doubled during potassium stimulation, amounting to $40 \%$ of total (both $\mathrm{L}$ and $\mathrm{D}$ ) aspartate, whereas its concentration detected in tissue extract was considerably lower than that of L-Asp by ca. two orders of magnitude (Table 1).

Table 1

Concentrations of Asp and Glu in dialysate samples in relation to experimental treatment, and in tissue homogenates from the medial striatum of domestic chicks

\begin{tabular}{|l|c|c|c|c|c|}
\hline & D-Asp (nmol/g) & L-Asp (nmol/g) & L-Glu (nmol/g) & L-Asp ratio (\%) & $\begin{array}{c}\text { D-Asp ratio } \\
(\%)\end{array}$ \\
\hline $\begin{array}{l}\text { Microdialysis baseline } \\
\text { samples (1-3 in Fig. 3) }\end{array}$ & $104 \pm 45$ & $397 \pm 75$ & $3585 \pm 1356$ & $23.8 \pm 5.7$ & $19.0 \pm 7.8$ \\
\hline $\begin{array}{l}\text { Microdialysis water } \\
\text { stimul. }\end{array}$ & $149 \pm 55$ & $598 \pm 101$ & $4050 \pm 1203$ & $27.1 \pm 6.2$ & $21.0 \pm 8.0$ \\
\hline $\begin{array}{l}\text { Microdialysis KCl } \\
\text { stimul. }\end{array}$ & $467 \pm 153$ & $819 \pm 185$ & $6123 \pm 1608$ & $25.4 \pm 6.2$ & $37.0 \pm 10.8$ \\
\hline Tissue homogenate & $30 \pm 2.2$ & $2308 \pm 217$ & $8644 \pm 632$ & $21.8 \pm 0.9$ & $1.3 \pm 0.07$ \\
\hline
\end{tabular}

The concentrations are expressed as nmol/g wet tissue weight (for brain extracts), or $\mathrm{nmol} / \mathrm{g}$ (i.e. $\mathrm{nmol} / \mathrm{ml}$ ) for microdialysates (mean \pm S.E.M). L-Asp ratio: $100 \times[$ L-Asp/(L-Asp+L-Glu)]; D-Asp ratio: $100 \times[D-A s p /$ (D-Asp+L-Asp)].

\section{DISCUSSION}

\section{L-amino acids}

The analytical method applied in the present study enabled the monitoring of minor local changes of EAAs in the brain. Our detection method used for tissue samples did not distinguish between intra- and extracellular amino acids but it excluded proteinbound amino acids from the analysis. By the other approach, in vivo microdialysis, selective measurement of extracellular L-Glu and L-Asp was made possible. The recently introduced method of chiral separation ensured that, unlike in our previous report [45], the L enantiomers of EAAs could selectively be assessed. These amino acids in their free form may either play a role in synaptic transmission (as neurotransmitters or neuromodulators) or they may also represent signaling molecules, e.g. for brain development.

Given the anatomical foundation $[1,18,19]$ for correlated action of EAAs, at least in the striatal/Ac regions [45] of chicks (together with electrophysiological evidence on potential interplay between Asp and Glu at the receptor/transporter level, see the study by Balázs et al. [2] on striatal slices), it seemed to be important first to assess the occurrence and distribution of free (unbound) L-Asp and L-Glu in the brain of the domestic chicken, together with the pattern of postembryonic development. 
The concentrations of L-Glu and L-Asp in the chicken did not show monotonous (monophasic) age-specific changes (as did D-Asp, see below). Instead, over the entire period of observation, there appeared one remarkable trough (valley) around day 4, whereas the values were rather uniform before or after this time. Notably, this period of reduced EAA may coincide with the closure of the sensitive period for early adaptive learning (e.g. taste aversion learning, imprinting) [4, 22, 25, 36].

Our study on the regional distribution of L-amino acids was focused on three of those regions which are known to participate in imprinting or passive avoidance learning of chicks $[5,22,36]$ the intermediate medial mesopallium (iMM), medial striatum/accumbens ( $\mathrm{mSt}$ ) and the arcopallium (Arco). Cb was used as control region. In the $\mathrm{mSt} / \mathrm{Ac}$ region, the concentration of L-Glu proved to be lower than in other regions, in independent datasets (see Fig. 2 and passive avoidance results). This finding makes sense, since the $\mathrm{mSt} / \mathrm{Ac}$ contains mostly medium spiny GABAergic neurons and abundant excitatory terminals (containing Glu and Asp) but practically no Gluergic/Aspergic perikarya.

Selective determination of L-Glu and L-Asp in microdialysis samples collected from the chick $\mathrm{mSt} / \mathrm{Ac}$ region enabled a more precise reproduction of our previous finding on correlated, predominantly synaptic, release of L-Asp and L-Glu [45], including a surge evoked by high potassium. Moreover, in the present study, a correlated phasic elevation of L-Asp and L-Glu was elicited not only by handling stress, i.e. aversive stimulus (as shown before, [45]) but also in response to an appetitive reward stimulus. Correlated amino acid response to an appetitive stimulus may represent another robust argument supporting the importance of Asp-Glu co-release in the avian basal ganglia.

\section{D-amino acids}

No previous data are known to us on post-hatch D-Asp levels in the brain regions of domestic chicks, yet the $0.03-0.04 \mu \mathrm{mol} / \mathrm{g}$ concentration, measured in different brain regions in the 2-day-old chicks (Fig. 2) is lower than the $0.4 \mu \mathrm{mol} / \mathrm{g}$, reported by Neidle and Dunlop [30] for the whole brain of the 20-day-old chick embryo (recalculated in D'Aniello [7]). In brain microdialysates, the D-asp/Total Asp ratio was found to be $17-18 \%$ (our calculation based on the published data by Punzo et al. [33]), whereas the same ratio in our current study was $19 \%$ (Table 1).

To our knowledge, the present study is the first report on dynamic changes of D-Asp in the extracellular space, using in vivo microdialysis combined with a high specificity chiral separation procedure for the analysis of samples [42]. Surprisingly, while water reward failed to increase D-Asp, high potassium brought about a marked elevation of D-Asp, when compared to baseline values. Unlike with the L-EAAs, the robust peak after high potassium stimulus was more protracted in the case of D-Asp, the elevation phase lasting well over an hour before returning to near-baseline value. This would indicate an activation of some secondary mechanism, temporally sepa- 
rated from the first stimulus of $\mathrm{K}^{+}$, whereas L-EAAs respond more immediately to high potassium. Whilst the abrupt surge of L-EAAs is in harmony with synaptic vesicular release, corroborating our previous report [45], the different time course of D-Asp elevation indicates a different storage, release or clearance mechanism. In particular, a contingent of the released D-Asp may be non-vesicular or even nonneuronal, similarly to the situation with D-serine (for review see Radzishevsky et al. [34]). Furthermore, the present results indicate that, while tissue content of D-Asp is a great deal less than that of L-Asp (by ca. two orders of magnitude), a surprisingly high percentage of tissue D-Asp gets released into the extracellular space, and, at the peak of high potassium response, the $\mathrm{D}$ enantiomer may constitute well over a third of total extracellular aspartate. By contrast, L-Asp (as indeed L-Glu) is far more abundant in tissue, and only a small fraction of it can be released on stimulation (Table 1), which is why any changes [6] in L-EAA flux accompanying passive avoidance training are likely masked by the huge non-specific pools of L-Glu and L-Asp, when measured in whole tissue samples.

In the present study, passive avoidance training did not cause detectable changes of the tissue concentration of free D-Asp in the regions known to be responsible for memory formation ( $\mathrm{mSt}$, iMM), or in other telencephalic and subtelencephalic regions $(\mathrm{Arco}, \mathrm{Cb})$ within the $24 \mathrm{~h}$ time window observed. One possible explanation is that the high level of D-Asp in the brain of young domestic chicks (Fig. 2) does not depend on behavioural stimulation. Rather, it is required as a tonic stimulus to maintain synaptic plasticity for early learning mechanisms $[29,36,38,40]$. The lack of elevation of extracellular D-Asp after positive reinforcement stimulus (in the microdialysis study) also suggests that D-Asp is not an immediate signal transducer for actual behavioural responses.

Unlike D-serine, an important co-agonist of NMDA receptors [20,37] (similar to glycine), D-Asp has a more direct affinity to the main glutamate binding site of the NMDA receptor (similar to the artificial ligand NMDA) [9, 14, 44]. A substantial contingent (ca. one third) of total aspartate might appear in the extracellular space in the form of D-Asp, at least at the peak of potassium-evoked response (as reported here). Contribution of D-Asp may partially explain our earlier observation [45] on the increase of extracellular Asp/Glu ratio during evoked release. How (and if) this process could be related to synaptic plasticity is yet to be clarified. In any case, D-Asp has been shown to enhance cognitive capabilities [12, 31, 39], and to improve synaptic plasticity [13].

In summary, tissue concentration of D-Asp shows marked changes during the first week of age of the domestic chicken with no considerable regional variation. This needs to be taken into account in any experiment investigating the role of this amino acid in synaptic plasticity during early learning (imprinting, taste aversion learning). Furthermore, with any extracellular measurement of aspartic acid one needs to consider that a significant amount of released Asp belongs to the $\mathrm{D}$ enantiomer. 


\section{ACKNOWLEDGEMENT}

Grant sponsors: Hungarian National Research, Development and Innovation Office (OTKA K109077, 63415) and Támop-4.2.1/B-09/1/KMR.

\section{REFERENCES}

1. Ádám, A. S., Csillag, A. (2006) Differential distribution of L-aspartate- and L-glutamateimmunoreactive structures in the arcopallium and medial striatum of the domestic chick (Gallus domesticus). J. Comp. Neurol. 498, 266-276.

2. Balázs, D., Csillag, A., Gerber, G. (2012) L-aspartate effects on single neurons and interactions with glutamate in striatal slice preparation from chicken brain. Brain Res. 1474, 1-7.

3. Bálint, E., Csillag, A. (2007) Nucleus accumbens subregions: hodological and immunohistochemical study in the domestic chick (Gallus domesticus). Cell Tissue Res. 327, 221-230.

4. Bateson, P. (1966) The characteristics and context of imprinting. Biol. Rev. 41, 177-220.

5. Csillag, A. (1999) Striato-telencephalic and striato-tegmental circuits: relevance to learning in domestic chicks. Behav. Brain Res. 98, 227-236.

6. Daisley, J. N., Gruss, M., Rose, S. P. R., Braun, K. (1998) Passive avoidance training and recall are associated with increased glutamate levels in the intermediate medial hyperstriatum centrale of the day-old chick. Neural Plast. 6, 53-61.

7. D'Aniello, A. (2007) D-Aspartic acid: an endogenous amino acid with an important neuroendocrine role. Brain Res. Rev. 53, 215-234.

8. D'Aniello, A., Guiditta, A. (1977) Identification of D-aspartic acid in the brain of Octopus vulgaris Lam. J. Neurochem. 29, 1053-1057.

9. D'Aniello, S., Somorjai, I., Garcia-Fernàndez, J., Topo, E., D’Aniello, A. (2011) D-Aspartic acid is a novel endogenous neurotransmitter. FASEB J. 25, 1014-1027.

10. Dermon, C. R., Zikopoulos, B., Panagis, L., Harrison, E., Lancashire, C. L., Mileusnic, R., Stewart, M. G. (2002) Passive avoidance training enhances cell proliferation in 1-day-old chicks. Eur. J. Neurosci. 16, 1267-1274.

11. Dunlop, D. S., Neidle, A., McHale, D., Dunlop, D. M., Lajtha, A. (1986) The presence of free D-aspartic acid in rodents and man. Biochem. Biophys. Res. Commun. 141, 27-32.

12. Errico, F., Rossi, S., Napolitano, F., Catuogno, V., Topo, E., Fisone, G., D’Aniello, A., Centonze, D., Usiello, A. (2008) D-aspartate prevents corticostriatal long-term depression and attenuates schizophrenia-like symptoms induced by amphetamine and MK-801. J. Neurosci. 28, 10404-10414.

13. Errico, F. et al. (2014) Free D-aspartate regulates neuronal dendritic morphology, synaptic plasticity, gray matter volume and brain activity in mammals. Transl. Psychiatry 4, e417.

14. Fagg, G. E., Matus, A. (1984) Selective association of N-methyl aspartate and quisqualate types of L-glutamate receptor with brain postsynaptic densities. Proc. Natl. Acad. Sci. USA 81, 6876-6880. 15. Fujii, N. (2005) D-amino acid in elderly tissues. Biol. Pharm. Bull. 28, 1585-1589.

16. Gibbs, M., Johnston, A. N. B., Mileusnic, R., Crowe, S. F. (2008) A comparison of protocols for passive and discriminative avoidance learning tasks in the domestic chick. Brain Res. Bull. 76, 198-207.

17. Gundersen, V., Storm-Mathisen, J. (2000) Chapter II Aspartate-neurochemical evidence for a transmitter role. In: Ottersen, O. P., Storm-Mathisen, J. (eds), Handbook of Chemical Neuroanatomy, vol. 18. Amsterdam, Elsevier. pp. 45-62.

18. Hanics, J., Bálint, E., Milanovich, D., Zachar, G., Adám, A., Csillag, A. (2012) Amygdalofugal axon terminals immunoreactive for L-aspartate or L-glutamate in the nucleus accumbens of rats and domestic chickens: a comparative electron microscopic immunocytochemical study combined with anterograde pathway tracing. Cell Tissue Res. 350, 409-423.

19. Hanics, J., Teleki, G., Alpár, A., Székely, A. D., Csillag, A. (2016) Multiple amygdaloid divisions of arcopallium send convergent projections to the nucleus accumbens and neighboring subpallial amyg- 
dala regions in the domestic chicken: a selective pathway tracing and reconstruction study. Brain Struct. Funct. 222, 301-315.

20. Hashimoto, A., Kumashiro, S., Nishikawa, T., Oka, T., Takahashi, K., Mito, T., Takashima, S., Doi, N., Mizutani, Y., Yamazaki, T., Kaneko, T., Ootomo, E. (1993) Embryonic development and postnatal changes in free D-aspartate and D-serine in the human prefrontal cortex. J. Neurochem. 61, 348-351.

21. Hashimoto, A., Oka, T., Nishikawa, T. (1995) Anatomical distribution and postnatal changes in endogenous free D-Aspartate and D-Serine in rat-brain and periphery. Eur. J. Neurosci. 7, 1657-1663.

22. Horn, G. (2004) Pathways of the past: the imprint of memory. Nat. Rev. Neurosci. 5, 108-120.

23. Ito, T., Hayashida, M., Kobayashi, S., Muto, N., Hayashi, A., Yoshimura, T., Mori, H. (2016) Serine racemase is involved in D-aspartate biosynthesis. J. Biochem. 160, 345-353.

24. Matsushima, T., Izawa, E.-I., Yanagihara, S. (2001) D1-receptor dependent synaptic potentiation in the basal ganglia of quail chick. NeuroReport 12, 2831-2837.

25. McCabe, B. J. (2013) Imprinting. Interdiscip. Rev. Cogn. Sci. 4, 375-390.

26. Mezey, S., Krivokuca, D., Balint, E., Adorjan, A., Zachar, G., Csillag, A. (2012) Postnatal changes in the distribution and density of neuronal nuclei and doublecortin antigens in domestic chicks (Gallus domesticus). J. Comp. Neurol. 520, 100-116.

27. Miller J. A. (1950) Do tumor proteins contain D-amino acids? A review of the controversy. Cancer Res. 10, 65-72.

28. Nadler, J. V., Vaca, K. W., White, W. F., Lynch, G. S., Cotman, C. W. (1976) Aspartate and glutamate as possible transmitters of excitatory hippocampal afferents. Nature 260, 538-540.

29. Nakamori, T., Maekawa, F., Sato, K., Tanaka, K., Ohki-Hamazaki, H. (2013) Neural basis of imprinting behavior in chicks. Dev. Growth Differ. 55, 198-206.

30. Neidle, A., Dunlop, D. S. (1990) Developmental changes in free D-aspartic acid in the chicken embryo and in the neonatal rat. Life Sci. 46, 1517-1522.

31. Nuzzo, T. et al. (2017) Decreased free D-aspartate levels are linked to enhanced D-aspartate oxidase activity in the dorsolateral prefrontal cortex of schizophrenia patients. npj Schizophrenia 3, 16.

32. Puelles, L. (2007) The chick brain in stereotaxic coordinates. Academic Press, San Diego.

33. Punzo, D., Errico, F., Cristino, L., Sacchi, S., Keller, S., Belardo, C., Luongo, L., Nuzzo, T., Imperatore, R., Florio, E., De Novellis, V., Affinito, O., Migliarini, S., Maddaloni, G., Sisalli, M. J., Pasqualetti, M., Pollegioni, L., Maione, S., Chiariotti, L., Usiello, A. (2016) Age-related changes in D-Aspartate oxidase promoter methylation control extracellular D-Aspartate levels and prevent precocious cell death during brain aging. J. Neurosci. 36, 3064-3078.

34. Radzishevsky, I., Sason, H., Wolosker, H. (2013) D-serine: physiology and pathology. Curr. Opin. Clin. Nutr. Metab. Care. 16, 72-75.

35. Reiner, A. (2004) Revised nomenclature for avian telencephalon and some related brainstem nuclei. J. Comp. Neurol. 473, 377-414.

36. Rose, S. P. (2000) God's organism? The chick as a model system for memory studies. Learn. Mem. $7,1-17$.

37. Schell, M. J., Cooper, O. B., Snyder, S. H. (1997) D-aspartate localizations imply neuronal and neuroendocrine roles. Proc. Natl. Acad. Sci. USA 94, 2013-2018.

38. Stewart, M. G., Rusakov, D. A. (1995) Morphological changes associated with stages of memory formation in the chick following passive avoidance training. Behav. Brain Res. 66, 21-28.

39. Topo, E., Soricelli, A., Di Maio, A., D’Aniello, E., Di Fiore, M. M., D’Aniello, A. (2010) Evidence for the involvement of D-aspartic acid in learning and memory of rat. Amino acids 38, 1561-1569.

40. Venero, C., Sandi, C. (1997) Effects of NMDA and AMPA receptor antagonists on corticosterone facilitation of long-term memory in the chick. Eur. J. Neurosci. 9, 1923-1928.

41. Wagner, Z., Tabi, T., Zachar, G., Csillag, A., Szoko, E. (2011) Comparison of quantitative performance of three fluorescence labels in CE/LIF analysis of aspartate and glutamate in brain microdialysate. Electrophoresis 32, 2816-2822. 
42. Wagner, Z., Tabi, T., Jako, T., Zachar, G., Csillag, A., Szoko, E. (2012) Chiral separation and determination of excitatory amino acids in brain samples by CE-LIF using dual cyclodextrin system. Anal. Bioanal. Chem. 404, 2363-2368.

43. Wolosker, H., D’Aniello, A., Snyder, S. H. (2000) D-aspartate disposition in neuronal and endocrine tissues: ontogeny, biosynthesis and release. Neuroscience 100, 183-189.

44. Yamanaka, M., Miyoshi, Y., Ohide, H., Hamase, K., Konno, R. (2012) D-Amino acids in the brain and mutant rodents lacking D-amino-acid oxidase activity. Amino Acids 43, 1811-1821.

45. Zachar, G., Wagner, Z., Tabi, T., Balint, E., Szoko, E., Csillag, A. (2012) Differential changes of extracellular aspartate and glutamate in the striatum of domestic chicken evoked by high potassium or distress: An in vivo microdialysis study. Neurochem. Res. 37, 1730-1737.

46. Zachar, G., Tóth, A. S., Balogh, M., Csillag, A. (2017) Effect of nucleus accumbens lesions on socially motivated behaviour of young domestic chicks. Eur. J. Neurosci. 45, 1606-1612. 